\title{
Obituary for Prof. Dr. Habil. Wolfgang Karg
}

Udo Karg*

Hohe Kiefer 152, 14532 Kleinmachnow, Germany

*Corresponding author: Udo Karg, Hohe Kiefer 152, 14532 Kleinmachnow, Germany, E-mail: udo.karg@arcor.de

Received date: March 05, 2018; Accepted date: April 02, 2018; Published date: April 12, 2018

Copyright: (c) 2018 Karg U. This is an open-access article distributed under the terms of the Creative Commons Attribution License, which permits unrestricted use, distribution, and reproduction in any medium, provided the original author and source are credited.

Citation: Karg U (2017) Obituary for Prof. Dr. Habil Wolfgang Karg. J Phylogenetics Evol Biol 6: 198.

\section{Letter to the Editor}

On August 4th, 2016, Professor Dr. habil. Wolfgang Karg died at the age of 89 years. We lose a great acarologist who was worldwide known as a taxonomist of mesostigmatic mites.

Professor Karg was born 1927 on July 10th in Groningen, near Halberstadt in Germany. After returning from captivity of World War II, he finished secondary high school. He studied biology at Humboldt University in Berlin. After several years of working as a teacher, he was employed from 1955 at the Biological Central Institute, since 1972 at the Institute of Plant Protection Research and after its dissolution at the Institute of Integrated Pest Management of the Federal Biological Research Centre for Agriculture and Forestry in Kleinmachnow, near Potsdam. At first he focused his research on Collembola and then he moved quickly to Acarology, which became his special field of research until his death. He described more than 300 new predatory mite species from many regions of the world and studied intensively the predatory mites in apple orchards. His scientific work with more than 250 publications attained great international prestige. Eminently emphasis may be given two books, the authoritative reference for determination of predatory mites in Central Europe "Acari (Acarina), mites, suborder Anachtinochaeta (Parasitiformes). The free-living Gamasina (Gamasides), Predatory mites" published 1971 and the 2nd revised edition 1993 with the title "Acari (Acarina), mites, Parasitiformes (Anactinochaeta), Cohors Gamasina Leach, Predatory mites". The second emphasized book "Predatory mites, useful regulators in the ecosystem" was published 1994 as part of a project funded by the German Research Society.
Unfortunately Wolfgang Karg could fulfil his reputation as an internationally important scientist in the field of predatory mites in the GDR only partly. Publications in international journals had to be approved by the Academy of Agricultural Sciences. Missions in western countries had been refused. Particularly strange was the scientific correspondence, which could in principle take place only by the director of the institute, so that some acarologists need to doubt whether Mr. Karg exist at all. This changed only after the political changes in Germany. In 1990 for the first time Wolfgang Karg was able to participate in an international congress of Acarology, where he was a much sought conversational partner. This gave him joy and great satisfaction.

In appreciation of his nationally and internationally recognized achievements, he was awarded in 1990 by the Academy of Agricultural Sciences with the title of a professor. In 1993 his scientific oeuvre was honored with the Fabricius Medal of the German Society for General and Applied Entomology.

Even after his retirement, he continued his research in acarology. He corresponded worldwide, described new species and published scientific papers. His last publication finished shortly before his death.

We mourn a great scientist in acarological research. We will always commemorate his great knowledge, his researchers urge, his objectivity and his modesty and last but not least through his cheerful nature and his laugher. 